\title{
Social Networking on Climate Change
}

The IDEAL-EU Experience

\author{
Francesco Molinari ${ }^{\S}$, Erika Porquier \\ $\S^{\S}$ SmartIntuitions Ltd., Cyprus, fm@smartintuitions.com.cy

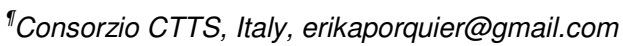

\begin{abstract}
This paper reports on the deployment of a multilingual Social Networking Platform in three regions of Europe (Catalonia, Poitou-Charentes and Tuscany), in the context of an EU-funded Preparatory Action on eParticipation dealing with the issue of climate change and energy policy making at the level of the European Parliament. The US ("Obama") approach and a novel ("European") usage of social networks in political online discourses are compared. A recommendation to policy makers is that social networking can be useful whenever the topics under discussion are limited in scope, but also wide in implications, so that they require moving forward from "one-off" and "ad-hoc" participation experiments, towards the permanent coverage of "mission critical" Public Administration functions.
\end{abstract}

Keywords: Climate change, eParticipation, Regions, Social Networking

Acknowledgement: The underlying research was made possible in part by a co-funding of the European Commission to the IDEAL-EU Project, a Preparatory Action in the area of eParticipation. However, the opinions expressed in this paper are solely of the authors and do not involve any of the EU institutions. We used Google Analytics ${ }^{\mathrm{TM}}$ to provide the statistics for the SNP traffic published here. A previous version of this paper was presented to the EDEM2010 conference in Krems, Austria. Special thanks go to the three anonymous reviewers for the useful insights received, which helped considerably improve the contents and approach. This new version includes an update of the SNP traffic in 2010, which, luckily, confirms rather than disconfirms the main thesis expressed in the paper.

A survey report by the Nielsen Company published in early 2010, referring to ten countries worldwide ${ }^{1}$, collected a number of global indicators and trends on social networking sites like Facebook, Linkedin, Myspace and Twitter. Worldwide, blogs and networking sites represent the most popular online category when ranked by average time spent, followed by online games and instant messaging. As of December 2009, "unique audience" and "average time spent per person" had followed similar dynamics, akin to the "early adopters" classification introduced by Rogers (1962), as the next two pictures show:

\footnotetext{
${ }^{1}$ Namely: Australia, Brazil, France, Germany, Italy, Japan, Spain, Switzerland, UK and US.
} 
Global Web Traffic to Social Networking Sites
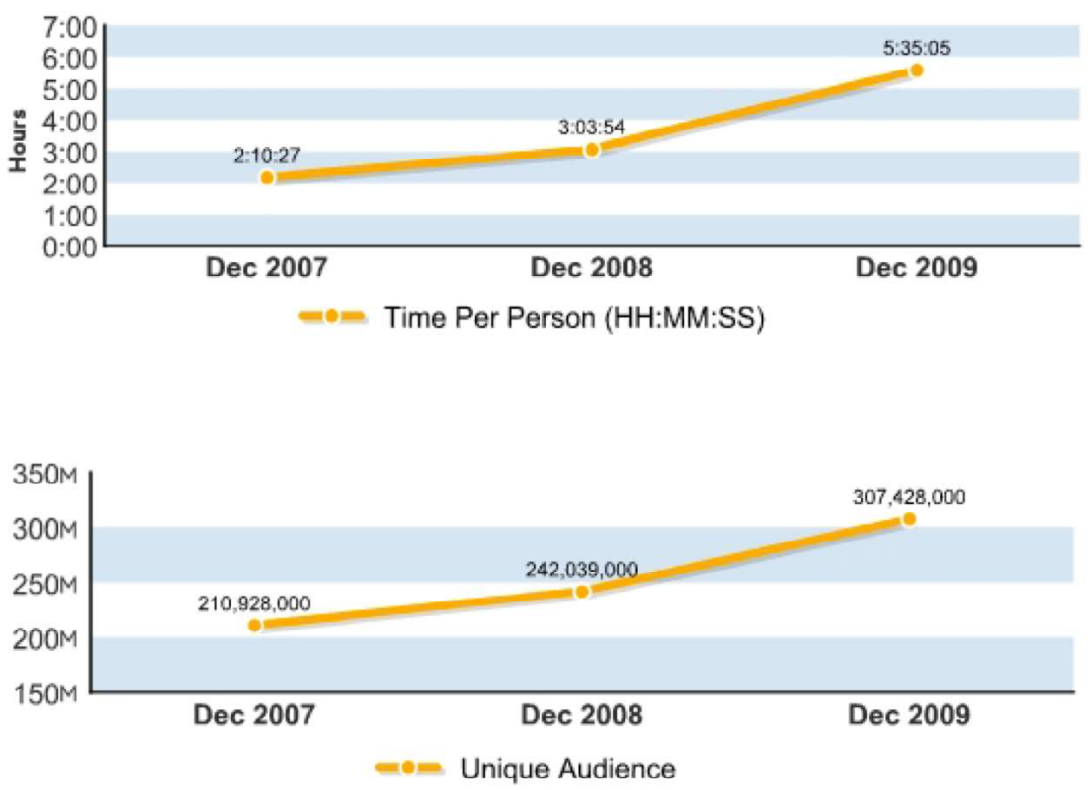

Figure 1: Recent trends in Social Networking worldwide (Nielsenwire 2010)

Looking at the bottom diagram first, with 307.4 million unique visitors (about two thirds of which are actually seen on Facebook), overall traffic exhibits a $46 \%$ increase in two years. In the same period, as the top graph displays, the average user is spending more time per month on social networks and blogs - five and a half hours at the end of 2009, with a 158\% progress over 2007.

In a similar vein, a previous analysis conducted at Morgan Stanley (2009) using 2008 data from the ComScore Digital World survey in the US, pointed at social networks as a "fast growth - low penetration" Internet category, or another example of Chris Anderson's (2004) "Iong tail" markets, as documented by the following picture:

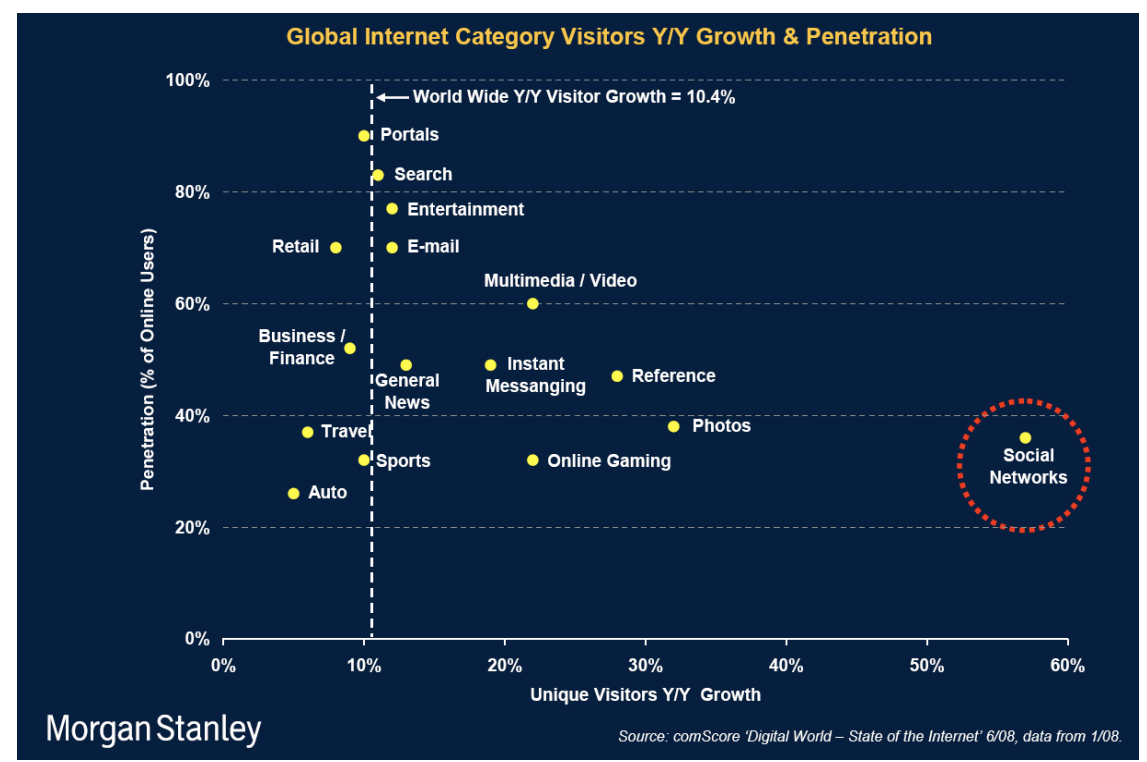

Figure 2: The "long tail" of social networks in the US (Morgan Stanley Research 2009) 
Such clear and consistent evidence poses an interesting dilemma: do the high growth rates in terms of unique visitors simply conceal the passing fad of a one-time phenomenon, or should we give more credit to the rapidly increasing average time spent on social networking sites, as reflection of a deeper trend into the personal habits of Internet users worldwide? To us, this dilemma hides an even more complex one, namely: should we start considering one-to-one, and possibly one-to-many interactions activated on "computer" networks as a complement, and possibly a valid extension, of "human" networks as we have known them for centuries till today?

Although this perception is not new (Wellmann 2001), we are still a long way ahead of gathering sufficient arguments for its support. For instance, renewed attention was recently gained by the results of old empirical research conducted in the 1990s by Prof. Robin Dunbar, an Anthropologist at the University of Oxford, on various social groups, from ancient villages to modern offices. He discovered that the neocortex in human brain, the one used for thinking and language, cannot cope with more than 150 friendships at the same time - a conclusion known as "Dunbar's number". This implies that social cohesion suffers within groups of friends ${ }^{2}$ larger than about 150 (Hill and Dunbar 2003). Revisiting the topic, Prof. Dunbar's view is that this number has not increased with the advent of online methods to keep in touch with friends, like Facebook, Bebo and Myspace. Comparing the online activity of Internet users with thousands and hundreds of friends, respectively, he concluded that there was no appreciable difference in their levels of activity.

"The interesting thing is that you can have 1,500 friends but when you actually look at traffic on sites, you see people maintain the same inner circle of around 150 people that we observe in the real world. [...] People obviously like the kudos of having hundreds of friends but the reality is that they're unlikely to be bigger than anyone else's", Prof. Dunbar observed. (WikiNews 2010)

Again, this evidence might be compelling in two opposite directions: either as a way to discard the (marginal or additional) value of "computer" networks as promoters of new forms of social interaction between human beings; or by a more subtle line of reasoning, to confirm that there is a strong continuity between the rules of personal behaviour in "virtual" and "real" communities, the former ones being suitable to become immediate and seamless expansions of the social sphere for every "connected" person on Earth.

Transferring the above dilemmas into the political sphere seems quite straightforward. All in all, getting involved in political discourses is one of the most common and frequent forms of "community networking", particularly within small and casually formed groups of people (i.e. what we sometimes call "bar chats"). Expressing judgements on a politician or supporting a political standpoint is a typical reason why people interact with their closest friends and speak out to the world around. This "word-of-mouth" chain has been known for decades to political campaigners and electoral marketers. The question becomes whether and to which extent technology can support and possibly magnify this effect, forcing the Dunbar number upwards and driving behavioural change, when it comes to personal and collective engagement in public life.

This is by no means a research oddity. After the Obama election, there seems to be no more doubt that at least in the US, social networking sites used to disseminate political agendas can effectively influence voters' behaviour. Independent studies (Marcelo et al. 2008) have highlighted the decisive contribution of young adults (between 18 and 29), 2 out of 3 voting for the Democratic candidate after being the age class with the highest number of people getting registered to the polls for the first time.

\footnotetext{
${ }^{2} \mathrm{~A}$ friend was defined as someone the individual cared about and made contact with at least yearly.
} 


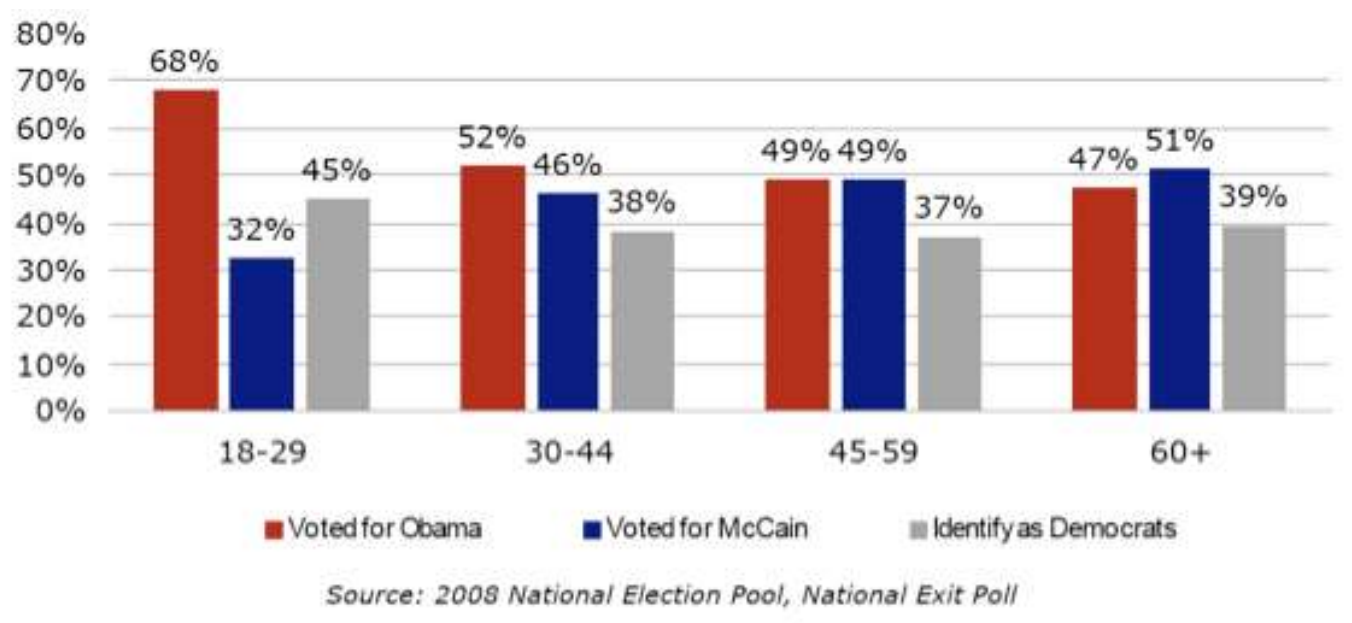

Figure 3: Voter preferences in US 2008 election by age class (Marcelo et al. 2008)

Back in 2007, the New Politics Institute, a US based think tank, published a speech by Chris Kelly, Chief Privacy Officer and Head of Global Public Policy at Facebook. According to him, the rise of "computer" networks could pragmatically assist politicos and advocacy organizations in five key areas:

- Branding (Obama is a brand), or have a meaningful presence on these sites to show that the candidate "gets it," where "it" is the radical transformation in modern media, particularly with young people;

- Voter registration, or the use widgets to support and make the process smoother for all age classes (in fact during the 2008 campaign, Facebook worked with Rock the Vote and Working Assets, two US advocacy NGOs, to develop an online application form for first time voters);

- Fund raising, or the use of social technology to activate networks of small amount donors (as Joe Trippi, manager of Howard Dean's 2004 campaign, regularly pointed out: "\$10 each from 10 million people is 100 million dollars", enough to provide a funding base for any presidential candidate);

- Volunteering, or to set up field operation events and invite people to join them (once formal friendship or group membership connections are established, mass messaging becomes relatively easy. RSVPs and actual attendance can be tracked and used for further outreach building towards election day);

- Last but not least Voter turnout: reaching out to potential and real supporters to make them go to the polls en masse is the ultimate goal of every such effort (Kelly 2007).

In this context, Europe as a whole seems to lag behind the US, both in terms of reported initiatives from the political side and of reliable documentation of their presumed behavioural effects. One interesting exception comes from a Preparatory Action on eParticipation funded by the European Commission in 2008 and 2009, the IDEAL-EU project. This was aimed to support the efforts of the European Parliament to raise awareness on the topic of climate change and energy among the EU citizens, especially the new generations, and to propose the most appropriate policy responses at all institutional levels (including EC, Member States and Regions). It did so in three main ways:

1) By deploying and disseminating in three regions of Europe (Catalonia - Spain, Poitou Charentes - France and Tuscany - Italy) an innovative Social Networking Platform, allowing the distribution of thematic information and the realisation of electronic debates, which has 
involved more than 1,200 citizens and Regional stakeholders, on the broad topic of climate change and energy in Europe;

2) By organising on $15^{\text {th }}$ November 2008 a Virtual Town Meeting, in three venues simultaneously (Barcelona, Firenze, and Poitiers), to let 546 young people discuss and vote on the most crucial issues at stake and on related recommendations to EU policy makers, in particular to the Temporary Committee on Climate Change ${ }^{3}$, chaired by MEP Guido Sacconi, whom the deliberation results were handed to three days later;

3) By laying the foundations of a European Network of Participatory Regions, based on the successful track record of experiences of the three Governments involved in the project, but open to a wider involvement of EU Regional authorities active on the good practices of (e-) Participation.

Despite some clear differences with respect to the US benchmark (no reference to a specific election round, the use of an "ad hoc" social network instead of leveraging on the most popular ones, "single issue" discussion and more generic finalisation of results), what we would like to document is the specific impact that the new ICT infrastructure has had on user behaviour, particularly after the end of the project trials.

To this purpose, the remainder of this paper is structured as follows: in Section 1 we report about the deployment and functioning of the IDEAL-EU Social Networking Platform (henceforth: SNP), during and after the project's end, based on some "indirect" indicators of user participation (Google Stats on traffic and a few statistics on the discussion threads); in Section 2 we introduce two further customisations of the IDEAL-EU SNP done at a local level in Tuscany; Section 3 discusses the results, and draws a recommendation for EU policy making.

\section{SNP deployment results}

The SNP developed by CTTS ${ }^{4}$, an Italian consortium of SMEs participating in the IDEAL-EU project as a partner, was designed in four languages - Catalan, English, French and Italian - and it is hosted at http://www.ideal-debate.eu/. Following is a screenshot of the English home page. The platform was developed using DRUPAL OSS based on the specifications received by the three Regions participating in the IDEAL-EU Project and is now available free of charge to all members of the European Network of Participatory Regions ${ }^{5}$.

\footnotetext{
${ }^{3}$ The CLIM Committee was created after a decision of $25^{\text {th }}$ April 2007 to set up a temporary committee on climate change. A decision on $18^{\text {th }}$ February 2008 of the European Parliament extended its term of office till $10^{\text {th }}$ February 2009 , when its mandate expired. The CLIM Committee produced two reports:

- In April 2008: "Draft Interim Report on the Scientific Facts of Climate Change: Findings and Recommendations for Decision-making";

- In December 2008: "2050: The Future begins Today. Recommendations for the EU's future Integrated Policy on Climate Change".

The latter report was adopted in plenary on $4^{\text {th }}$ February 2009 by 570 votes in favour, 78 against and 24 abstentions.

${ }^{4}$ CTTS (Consortium for Technology and Services in Tuscany; www.consorzioctts.it) is made up of three SMEs operating in the field of new technologies, ICT services for public administration and project management at local, national and European level.

${ }^{5}$ http://www.demo-part-org. CTTS (http://www.consorzioctts.it), the developing partner of the SNP, has issued a CD with all the source files, the SNP installation instructions and a User Manual.
} 


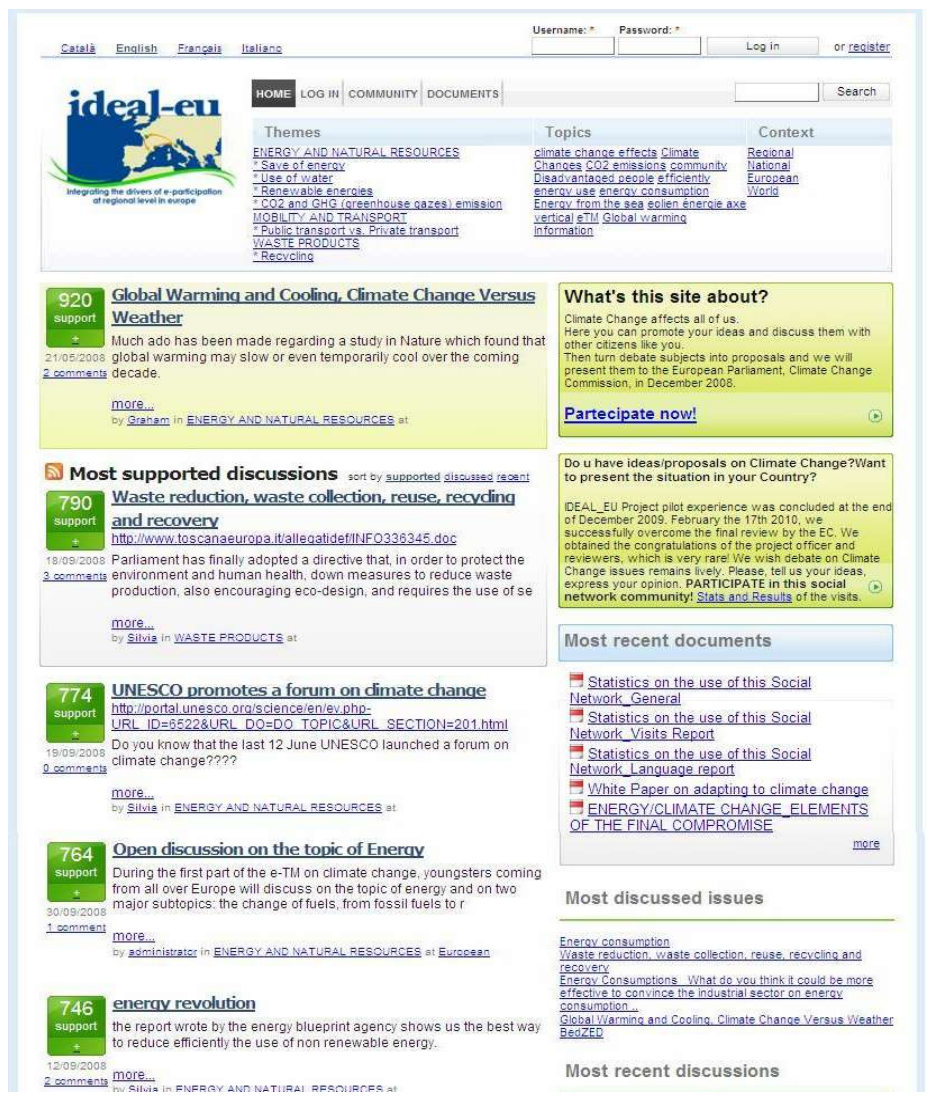

Figure 4: The IDEAL-EU Social Networking Platform

In order to achieve a local installation, the following third party software was required:

- Apache 1.3 (recommended 2.x) with extension mod_rewrite

- PHP 4.3.3 memory limit 12MB (recommended 16MB) with extensions mysql and mysqli and $\mathrm{XML}$ extensions enabled

- GD Library for PHP

- The following settings were needed on PHP:

- session.save_handler: user

- error_reporting set to E_ALL \& E_NOTICE. Work is ongoing to change this to E ALL for Drupal 6.

- session.cache_limiter: nocache (recommended)

- MySql 4.1 with an account allowing the following instructions: SELECT, INSERT, UPDATE, DELETE, CREATE, DROP, INDEX, ALTER, CREATE TEMPORARY TABLES, LOCK TABLES.

The national versions of the SNP intended to support the distribution of thematic information on the issues of climate change and energy and the realisation of deliberative discussions among citizens and stakeholders on the upcoming EU policy agenda. The idea was to boost citizens' interest and build up their awareness before engaging them in the discussion. By mid 2008, all the needed information was uploaded and is still available on the platform. Debates were freely open (to registered users), but moderated by experienced facilitators. 
The SNP was also used to draw the attention of Regional citizens (mostly young people) towards the Virtual Town Meeting ${ }^{6}$ of November $15^{\text {th }}, 2008$, and to encourage them to subscribe to and participate in the event. Furthermore, the SNP was used to prepare the Town Meeting agenda. Registered users were asked to choose the subjects they thought were worth discussing during the event. As a result, participation in the Virtual Town Meeting was even more qualified, because some attendees were already familiar with the subject matter and had their own convictions to share with other people. Here is an example of a question posed to users for agenda setting:

http://www.ideal-debate.eu/en/node/443

What do you think could be more effective to convince the industrial sector on energy consumption reduction? According to your opinion, are there any other reasons to support these questions apart from the following ones?

1. higher energy prices to force companies to reduce their consumptions;

2. economical incentives for the companies that opt for new technologies, energetically efficient:

3. laws to punish and avoid wastes;

4. a mandatory "energetic certification of goods", to inform the consumers on products produced by using less energy;

5. other?

What do you think about it? Please, write below your ideas and, if you think this is the most relevant subject for the discussion, support it!

And here is the reply of a user from Copenhagen:

Comment 1: In terms of prioritizing the above points it very much depends on the economic and political system in which you operate (eg the difference between the US and continental European ways of doing things). That said the two most effective would in my opinion be:

1) Higher energy prices eg through environmental taxes which should be earmarked for,

2) economic incentives to adopt new energy efficient technologies (which initially are often more expensive).

A successful example of the above approach is the development of the wind energy technology and use in Denmark.

By design, the SNP hosted four different kinds of user:

- Anonymous

- Registered

- Stakeholders (a specific type of registered users, belonging to an association, institution, political party, company, or NGO)

- Moderators (debate facilitators hired by the three Regions).

The main distinction was between Registered and Anonymous users ${ }^{7}$. Only the former could actively take part in the online debates, by suggesting new topics, taking part in the discussions, and giving their opinion on other users' comments by clicking on a "+" or "-" button. Anonymous

\footnotetext{
${ }^{6}$ A Town Meeting is a form of structured participation in local government practiced in the U.S. region of New England since colonial times, when an entire community was invited by government officials to gather in a public place to formulate suggestions or provide feedback on specific policy issues. In its modern version - the electronic/virtual Town Meeting- a dedicated web application makes it possible to support a similar interaction structure among hundreds of participants located in different venues in real time.

${ }^{7}$ Due to the extremely low requirements for registration (only a valid email address was needed) and to the massive presence of anonymous visitors, it was technically impossible to perform a systematic analysis of their demographic characters.
} 
users could only read the posts and intervene on the ranking of subjects using the polling mechanism. (A specific feature prevented them from voting more than once)

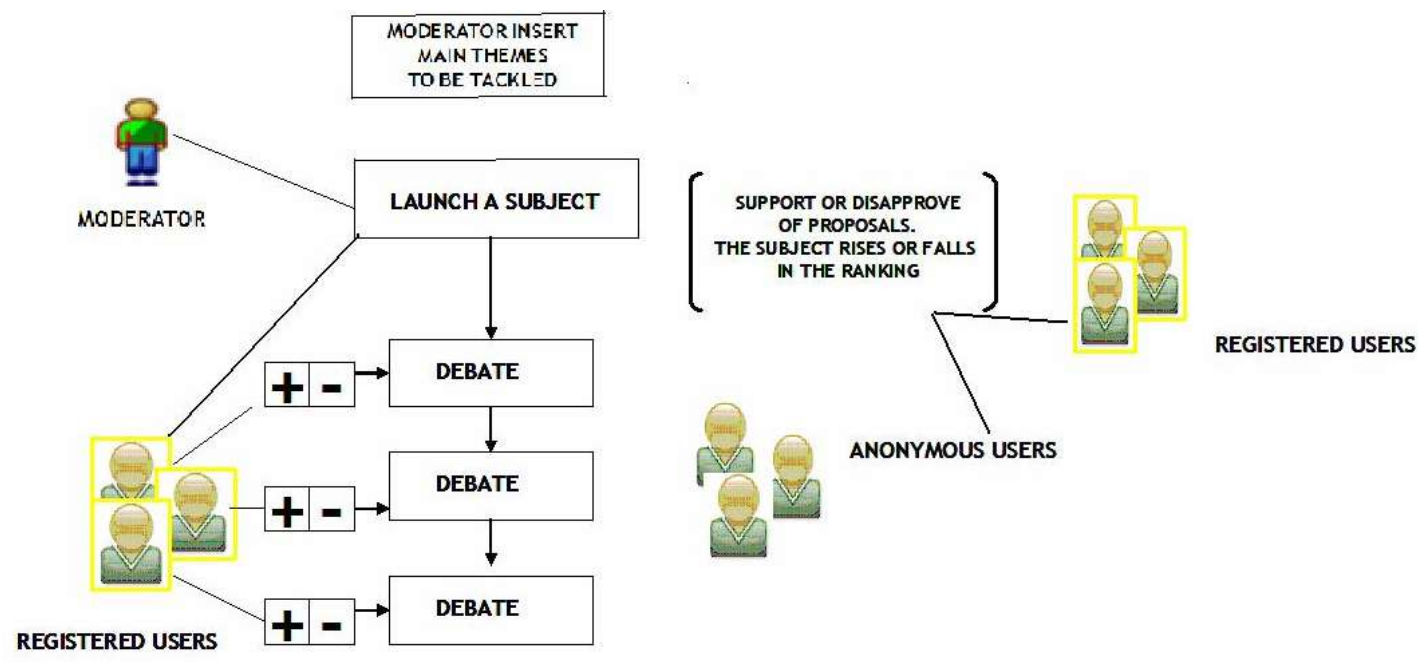

Figure 5: User roles on the IDEAL-EU SNP

In short, each debate on the SNP was made up of three stages:

1. Launching a discussion subject (new topic) through a specific post;

2. Inserting comments (on previous posts or on other users' comments);

3. Voting (to express approval or disapproval) on comments, proposals and/or discussion threads.

The platform was officially launched on $25^{\text {th }}$ June 2008. It is worth noting that three totally independent debates on climate change and energy took place on the SNP during the second half of that year (in Catalan, French, and Italian), while the English version was mostly used to disseminate the project results to a wider international audience. The four sections were all accessible from the SNP home page. Internet users could switch from one language to another and monitor the different platforms, which included totally different contents due to the national priorities identified by the three Regions and to the spontaneous evolution of the respective online debates. Overall coherence was maintained, however, thanks to a strong commitment from the Project Consortium on the actions to be carried out. To return to the above example, while organising the Virtual Town Meeting, the moderators published the same question in three languages, thus asking different national groups to reply to it.

One of the risks that social networks typically show, is that a number of people do not actually follow the discussion threads set up at the beginning. Contributions and topics (posted independently by the users) can easily digress from the initial subject matters. This did not occur in the IDEAL-EU SNP, probably due to the novelty of the issues dealt with.

During the period from July to November 2008, the three Regions actively "pushed" the subscription and active participation of young people and local stakeholders in the national version of the SNP, through a number of awareness raising and dissemination initiatives (IDEAL-EU Project 2008). As a result of this effort, the following data on attendance was collected until the end of the first year: 
Table 1: SNP Indicators (July-December 2008)

\begin{tabular}{|r|c|}
\hline \multicolumn{1}{|r|}{ Catalunya } & 196 \\
\hline Poitou-Charentes & 764 \\
\hline Othescana & 74 \\
\hline Other nationalities (English version) & 142 \\
\hline Total No. of Debates opened & $\mathbf{1 3 4}$ \\
\hline Total No. of Comments inputted & $\mathbf{2 , 3 7 2}$ \\
\hline No. of votes to the most supported discussion (Catalunya) & 371 \\
\hline No. of votes to the most supported discussion (Poitou-Charentes) & 509 \\
\hline No. of votes to the most supported discussion (Toscana) & 281 \\
\hline No. of votes to the most supported discussion (English version) & 684 \\
\hline Total No. of Visits (Anonymous + Registered Users) & $\mathbf{6 , 5 7 3}$ \\
\hline
\end{tabular}

These results might well have been provoked by the intense and intensive efforts provided by the Regions governing the SNP installation and start-up process. These reflected an unexpected evolution taken by the Project activities with respect to their initial timeline. Basically, the date of the Virtual Town Meeting, which was originally set in Spring 2009, had to be put forward to November $15^{\text {th }}, 2008$ in order to ensure that the CLIM Temporary Committee had time enough to include the results of that pan-European experiment into its final proceedings, which were scheduled for the end of the year. As a result, the time available for SNP animation and promotion was cut off by at least six months, and it is fair to admit that after the performance of the Town Meeting, no further initiative was taken by the Regions to attract more audience and interest on the SNP debates. This meant among other things, that no moderation was ensured any longer in the three national versions of the platform.

However, it is from this point that something unexpected happened. During the whole 2009, new users have continued to register and many more unique visitors have populated the content areas of the SNP. As the next table shows, 71 more debates have been spontaneously opened (about $50 \%$ those of the first year, which only lasted 6 months, however); 610 additional comments have been left (about $25 \%$ those of 2008), and 15,629 new visits have been counted, leading the overall number of contacts to a $250 \%$ increase with respect to the previous (half a) year. 
Table 2: SNP Indicators (January-December 2009)

\begin{tabular}{|c|c|}
\hline Increase in Registered users (end 2009 / end 2008) & +37 \\
\hline Catalunya & +3 \\
\hline Poitou-Charentes & +17 \\
\hline Toscana & +10 \\
\hline Other nationalities (English version) & +7 \\
\hline Additional Debates opened & +71 \\
\hline Additional No. of Comments inputted & +610 \\
\hline Additional No. of votes to the most supported discussion (Catalunya) & +160 \\
\hline Additional No. of votes to the most supported discussion (Poitou-Charentes) & +61 \\
\hline Additional No. of votes to the most supported discussion (Toscana) & +79 \\
\hline Additional No. of votes to the most supported discussion (English version) & +194 \\
\hline Additional No. of Visits (Anonymous + Registered Users) & $+15,629$ \\
\hline
\end{tabular}

As the next diagram displays, most of the traffic on the SNP took place in the last months of 2008, and particularly in the month of November, when the Virtual Town Meeting was actually organised. However, a relative peak is also visible in November-December 2009, presumably on the occasion of the Copenhagen Summit on Climate Change.

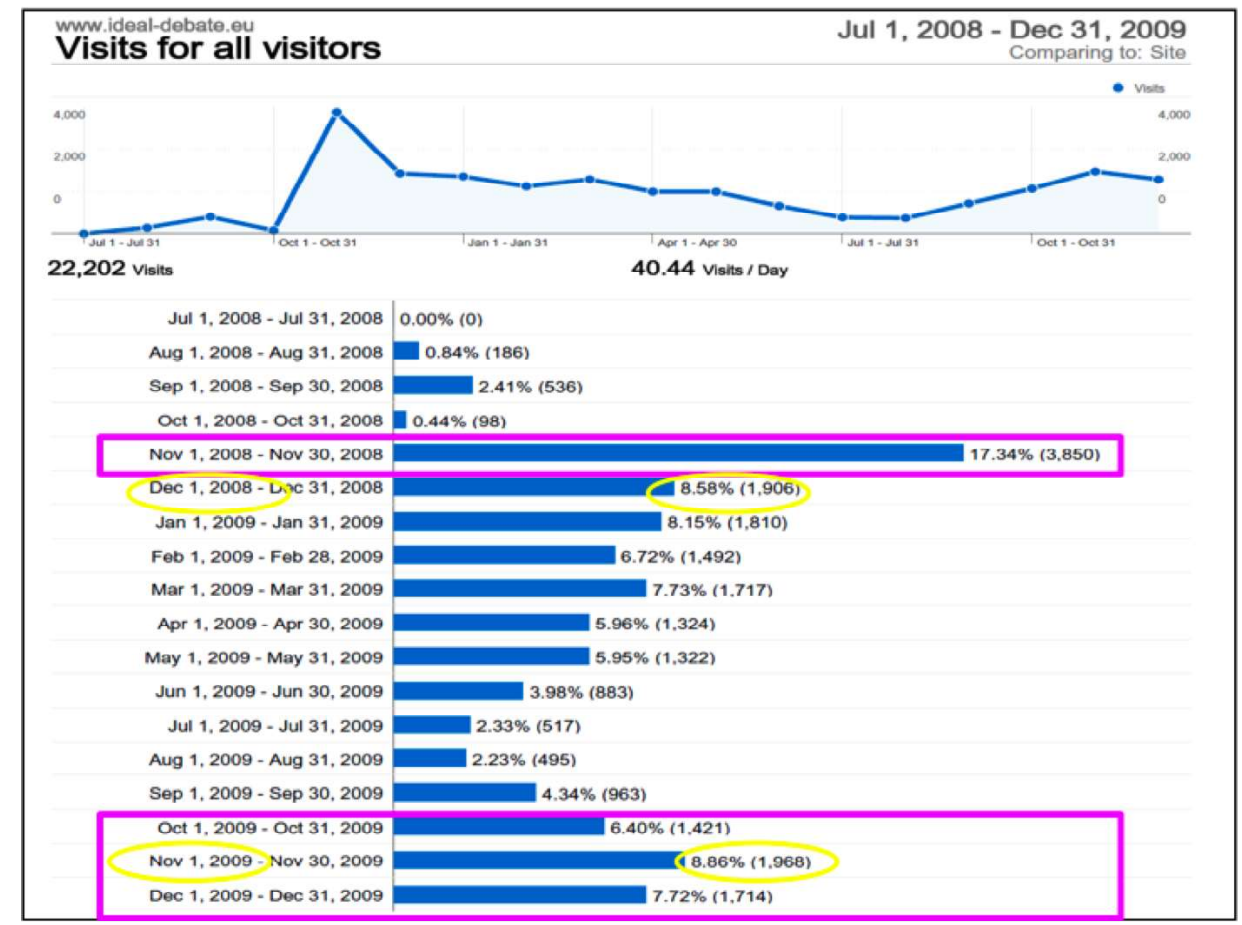

Figure 6: Traffic statistics on the IDEAL-EU SNP during the project

In fact, what site statistics show is that from 2008 to 2009 there has been, a reduction in direct traffic - i.e. traffic generated by users who clicked on the SNP website http://www.ideal-debate.eu/ directly or through the Project's website http://www.ideal-eu.net/. These people were most likely those directly and originally "recruited" by the three Regions for the organisation of the early SNP 
debates. Traffic now mainly comes from search engines by keyword. That is, Internet users who are interested in climate change and energy matters, look up these subjects using normal search engines. Since the SNP is well indexed on many search engines, people find links to it among their search results and then decide to visit the platform.

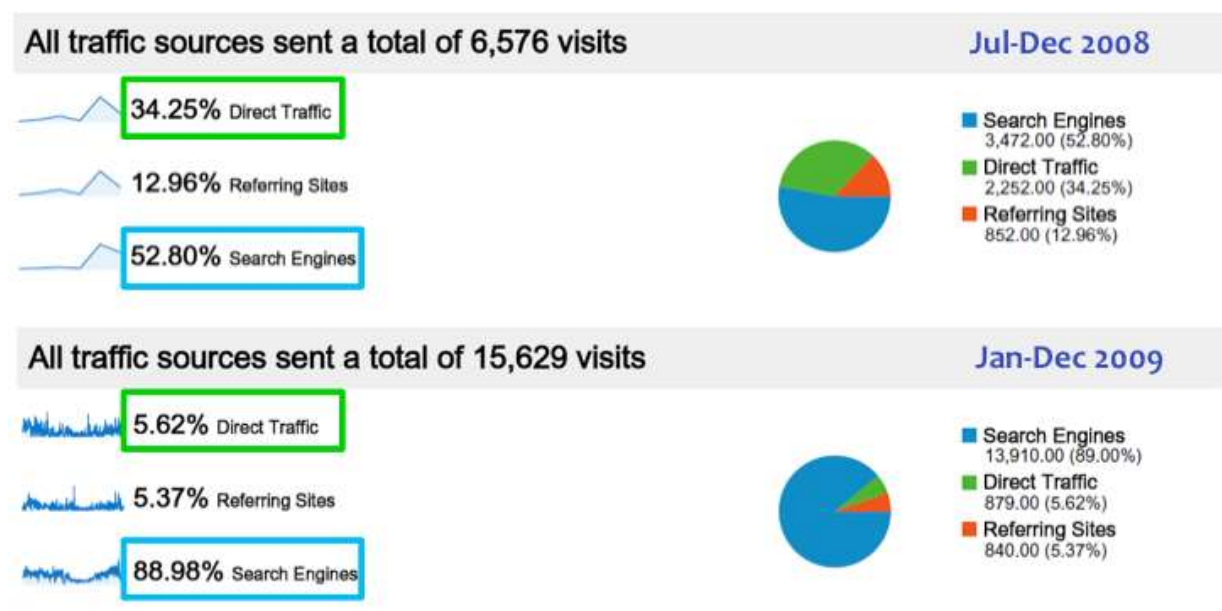

Figure 7: Traffic sources towards the IDEAL-EU SNP

As displayed in the diagram, one third of the 6,576 visits in 2008 came in from direct traffic, this percentage dropped to only one in twenty for the 15,629 visits of 2009. Traffic from referring sites remained steady in number, while the big increase was actually generated through search engines.

It is also worth noting that this latter typology of traffic was not occasional at all. For instance, if we consider a month of relatively low traffic, such as September 2009, the following table shows good evidence of the proactive behaviour of SNP visitors:

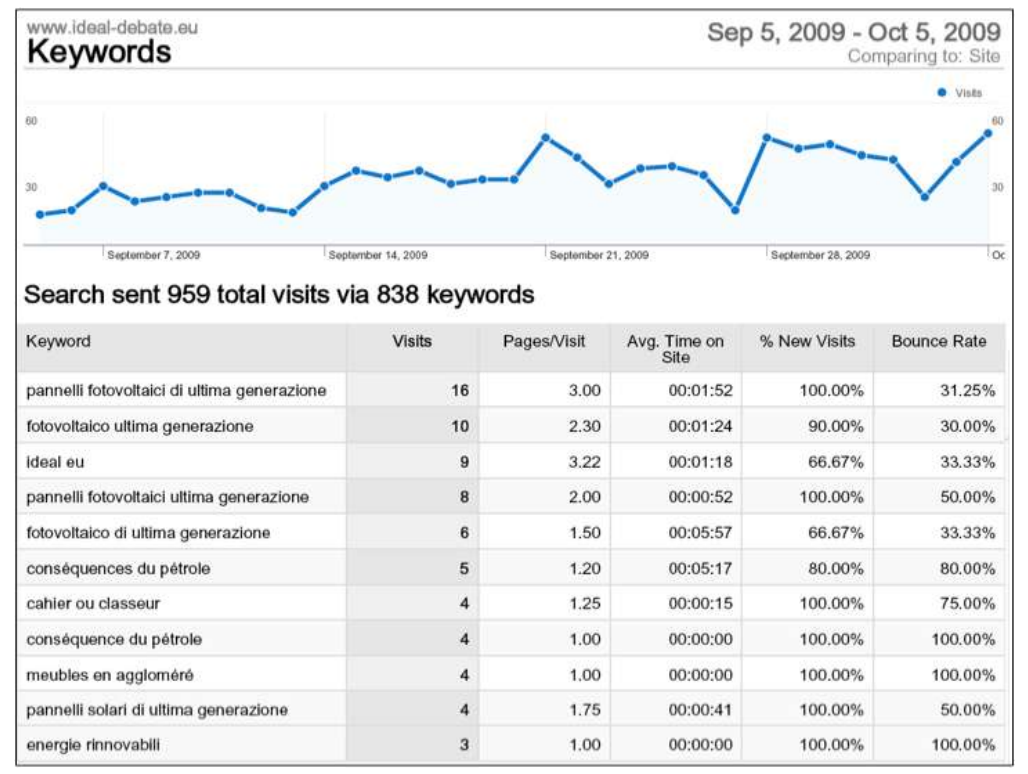

Figure 8: SNP indicators (September 2009)

As the picture exhibits, most topics consulted by SNP users were extremely precise (with 4 out of the first 5 keyword rows pointing at the photovoltaic energy issue, which was the subject of a Regional campaign at that time); the average time spent on the site was quite long, with a fairly low bounce rate and an average of more than one page per visit, indicating that activity on the SNP was meaningful and not occasional. 
Even in the course of 2010 and until late March 2011, when this paper has been revised, the reported movement did not stop, in spite of the conclusion of the IDEAL-EU project activities (the final review was held in February 2010) and the considerable length of time elapsed since the end of the Copenhagen Summit. As the next table and figures show, we have had 26 new users registered in the SNP, with 15 further discussion threads opened, 734 more votes casted (only to the most supported discussion thread) and 12,697 additional visits, by 11,822 absolutly unique visitors from 123 countries worldwide. Again, most of the traffic was channelled via search engines, and only $8 \%$ by direct hits.

Table 3: SNP Indicators (January 2010 - March 2011)

\begin{tabular}{|l|c|}
\hline Increase in Registered users (March 2011 / December 2009) & +26 \\
\hline Additional Debates opened & +15 \\
\hline Additional No. of Comments inputted & +11 \\
\hline Additional No. of votes to the most supported discussion (English version) & +734 \\
\hline Additional No. of Visits (Anonymous + Registered Users) & $+12,697$ \\
\hline
\end{tabular}

\section{www.ideal-debate.eu}

\section{Traffic Sources Overview}

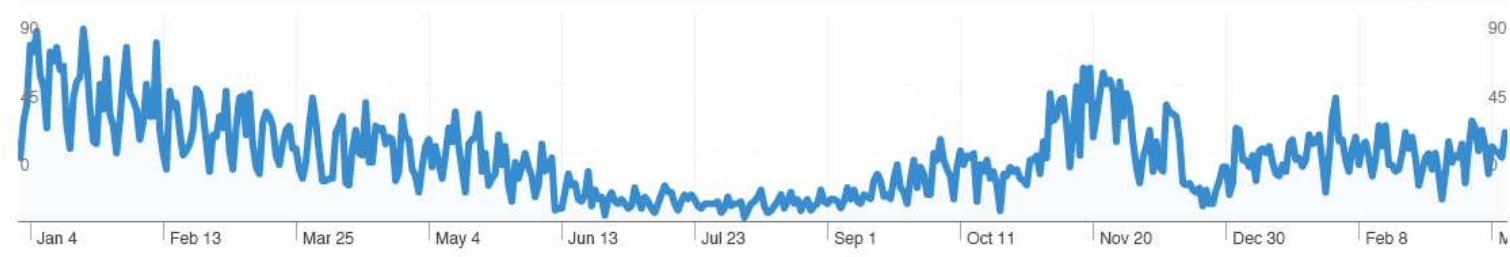

\section{All traffic sources sent a total of 12,697 visits}

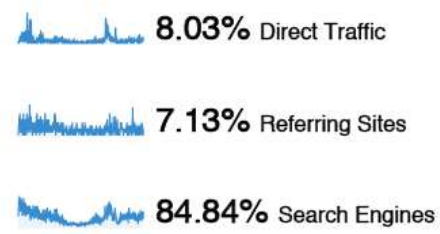

$$
\begin{aligned}
& \text { Search Engines } \\
& 10,772.00(84.84 \%) \\
& \text { Direct Traffic } \\
& 1,020.00(8.03 \%) \\
& \text { Referring Sites } \\
& 905.00(7.13 \%)
\end{aligned}
$$

Figure 9: Traffic statistics on the IDEAL-EU SNP after the project's end

\section{Discussion}

To sum up, the SNP showed its crucial importance for the IDEAL-EU project implementation, (at least) in three different respects:

a) By displaying and highlighting the most important subject matters and the key thematic issues at stake, as well as helping identify the most appreciated debate axes by SNP users, with a view to their possible replication in the Virtual Town Meeting. This first aspect proved particularly important in the Catalonia case. In this sense, it is worth mentioning the SNP feature allowing proposals prioritization through the voting mechanism;

b) By "self-selecting" the most active contributors, who were invited as participants in the Virtual Town Meeting as well. This second aspect - how to ease the identification of Town Meeting attendants - was particularly appreciated in the Poitou-Charentes case. The corresponding 
SNP features were the ranking of "top contributors" and the possibility of contacting them, without violating their anonymity and/or privacy rights, by making use of the valid email address they had provided upon registration;

c) By supporting the post-project monitoring and evaluation phase, not only with respect to climate change (as the SNP continued to be consulted during the second Project year), but more generally for the whole participatory policy of the Region. This third aspect better characterises the Tuscany case, where a further customisation of the SNP became another social network - Piazza Toscana ("Tuscany Square") - that is now being used to elicit public debates on the implementation of the recently approved Regional law on citizens participation in policy making.

This new platform went online in November 2008. It gained only 593 visits in the first month. An improved version was released on the occasion of the $1^{\text {st }}$ International Conference on Participatory Democracy held in Montaione ("Le giornate di Montaione": 12-13-14 November 2009), which was organized by the Regional Government itself.

Customisation was performed through the setup of a dedicated section for each eParticipation initiative locally organised by a municipality, a group of municipalities, or by the Tuscany Region itself. Each section contained all the related reference material (official documents, town plans, images, videos etc.). The citizens could comment on other participants' proposals and/or opinions expressed on the SNP, vote for the preferred citizens' comments, and publish their own proposals, petitions, or ideas even if unconnected with ongoing initiatives.

Unfortunately, the political agenda of the Regional Government has caused the Piazza Toscana project to be put on hold for a while. This has not meant, however, a reduction of interest in the promotion of grassroots eParticipation at a regional level, which is supported by a dedicated budget line of the Regional Government, in compliance with the provisions of Law No. 69 of 2007. 


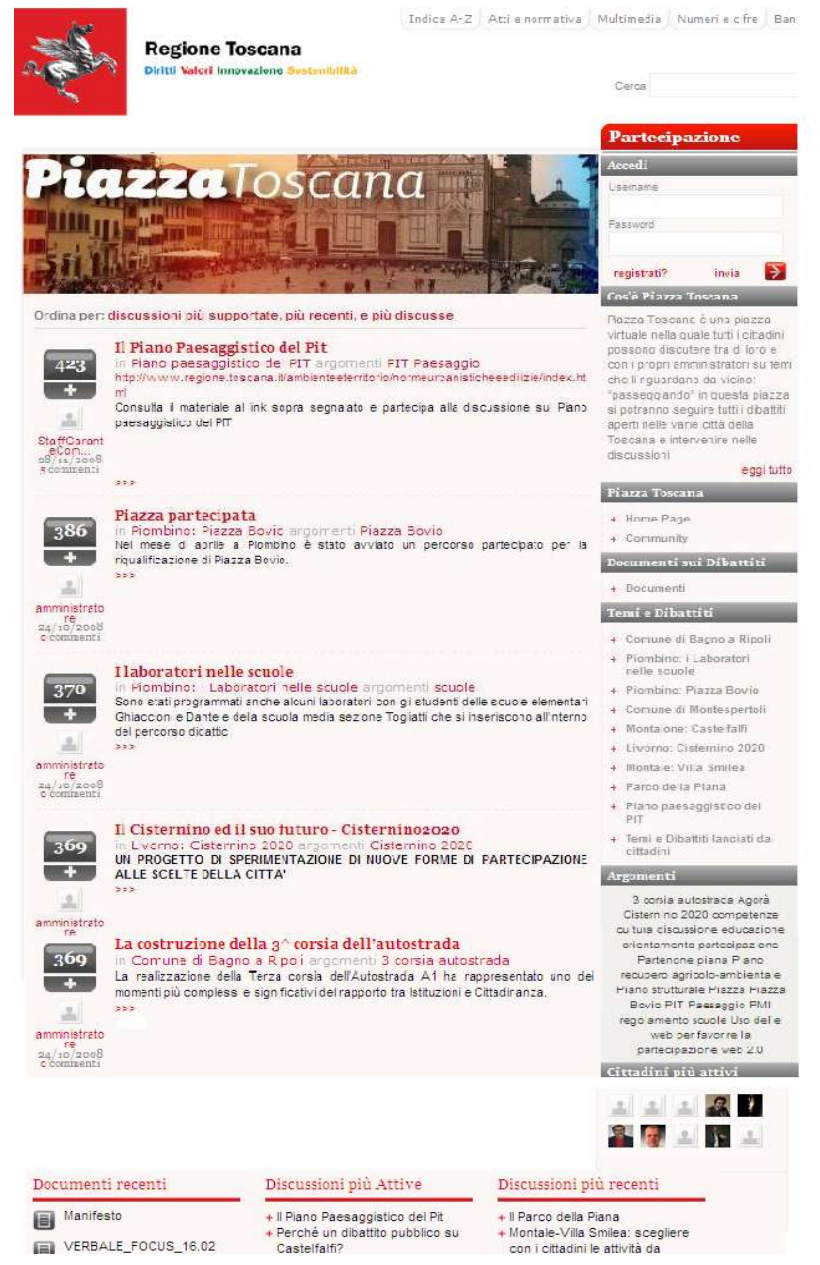

Figure 10: The "Piazza Toscana" home page ${ }^{8}$

Finally, CTTS autonomously replicated the SNP in another local eParticipation project, named PARTEMP ${ }^{9}$, where it was engaged as a technological partner and promoter. The new platform was adopted by the local health authority of the City of Prato, with the aim of encouraging free debates among citizens and local voluntary associations (43 in number) regarding the quality of information and communication about the services supplied by the health authority itself. A pilot started in early October 2009 (see next figure). The SNP was mostly used in that context to allow people and stakeholders co-designing new healthcare information and communication campaigns.

The PARTEMP project lasted only 25 days and is now closed. This small experience could not be considered significant, given the numbers involved. However, we decided to mention it for its impact, which can be defined as encouraging, especially considering that the audience was made up principally of middle-aged people with little experience of ICT. Also, $40 \%$ of the local voluntary associations participated in the online activities; but the real surprise was the quality of the inserted contents, so that the local health authority of Prato declared its intention to adopt one of the health care campaigns designed during the trial.

\footnotetext{
${ }^{8}$ http://www.regione.toscana.it/partecipazione

${ }^{9}$ PARTicipation and EMPowerment of people, http://partemp.us/4.toscana.it/
} 


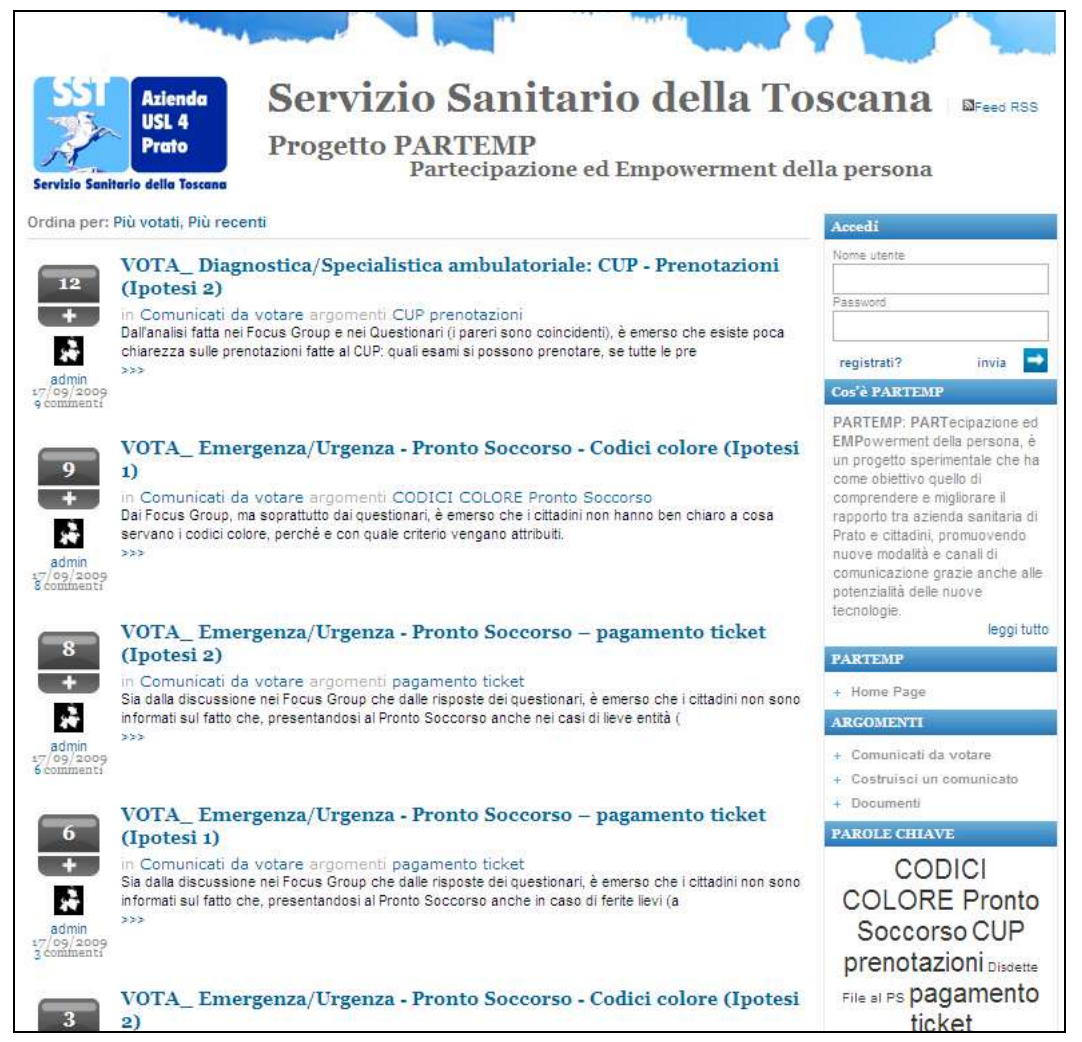

Figure 11: The PARTEMP Project home page

All of this evidence - both the IDEAL-EU SNP and its further customisations at a Regional level in Tuscany - testifies the important role played by the political commitment as "prime motor" (for good and bad) of the setting up and implementation of a social networking platform as a support to policy making. But the most unexpected, and somehow surprising, results come from the rather autonomous life that two years ago, the IDEAL-EU platform has started to live on, independently of any further initiatives by its original "owners".

$\mathrm{Be}$ it for the "explosion" of the climate change topic towards the end of 2009, mostly in relation with the Copenhagen Summit, or simply due to its good positioning on the search engines, the SNP has grown even faster now than it did in its early stages, while it was actively "pushed" by the supporting public authorities via a number of initiatives to raise awareness and elicit attendance, particularly from the young people residing in the three Regions involved in the IDEAL-EU Project.

While the number of subscriptions and the intensity of discussions cannot be compared to Facebook or other similar networking sites ${ }^{10}$, what is more interesting is a couple of "Iong tail" effects emerged out of the IDEAL-EU SNP experience: on the one hand, registered users since 2008 have continued to open up new threads of discussion during 2009 and 2010, even in the absence of moderation (or perhaps due to it?); on the other hand, the number of unique visitors to the platform has increased by $250 \%$ - driven by search engines and with the likely aim of getting more information on the various "hot" issues according to newspaper headlines.

Now, the reason why this information was searched for on the IDEAL-EU SNP may depend on its superior "credibility": the fact that it was built in the context of an EC-funded project, that was run by Regional Government(s), and the thematic information distributed on it was directly coming from the European Parliament in some way. But we think it possible to add a different interpretation: that

\footnotetext{
${ }^{10}$ This normally happens, by the way, with blogs and social networks linked by a single common interest; such as The Social Golfer (http://www.thesocialgolfer.com/), A Country Life (http://www.acountrylife.com/), Great Cooks Community and the like (http://www.greatcookscommunity.com/).
} 
is, the presence of lively debates has increased the reputation of the platform itself. Although we are missing any sort of direct evidence in this respect, we consider it as a plausible explanation, for a variety of indirect reasons:

- Reputation normally takes a lot of time to be established. But once someone starts being considered as credible, further recognition becomes easier and faster to get. This seems to be mirrored by the SNP statistics presented in this paper, with the number of contacts growing exponentially at least since the last quarter of 2009. As a result, it is our commitment to continue collecting and accumulating evidence on the IDEAL-EU platform traffic in the near future ${ }^{11}$;

- Social networking sites also rely on reputation building. There are two main ways to establish this: the first is to seek other people's recommendation or support; the second is to "exhibit" online what one actually does. We suspect that the SNP growth reported above may have taken the benefits of both channels to increase its credibility. In particular, the latter impact is confirmed by the wider use of the platform as a primary information source on climate change related topics. In order to gather some objective evidence on reputational aspects, an online survey was launched on the SNP itself towards the end of 2010, which is still ongoing.

\section{Conclusions}

To summarise, the research questions underlying this paper were threefold:

a) Are computer-based social networks a valid extension of those based on face-to-face interaction?

b) Can the former be of use for politicians and policy makers?

c) Are there any structural differences between the "US" and the "EU" approach (if any) to social networking in politics?

To respond to these questions, we have not carried out a systematic collection of evidence, but some hints from existing theories and practice have been shown.

In particular, the case study of the IDEAL-EU SNP seems to indicate the possible emergence of a "European way" of using social networking in political discourses online. This has more to do with the spontaneous discussions within groups of peers - the "bar chats" referred to in the Introduction - than the corresponding examples taken from the US electoral campaign of 2008, which mostly leveraged "generalist" social networks. In addition to that, despite being based on a single-issue platform, this experiment seems to lose much of the immediate, and sometimes viral, propagation strength of hacker attacks or Twitter based protests.

Thanks to the provision of advanced information to discussants, the judgements expressed during the debates look more reliable, perhaps even authoritative as a source. A "word-of-mouth" effect continues to spread over time, and the favourable impact of the platform start-up and trial phase (the one directly governed by the SNP owner) gets reinforced by subsequent one-time contacts and repeated (?) anonymous visits.

The following table compares five characters of successful social networks in Europe and US politics.

\footnotetext{
${ }^{11}$ It could be added at this stage that unfortunately, due to the strict protection of anonymity and privacy on the platform, it is also impossible to collect systematic evidence on the geographical origin of SNP participants, even if the language restriction obviously creates segmentation across the various national communities.
} 
Table 4: Political Social Networking Orientation in Europe and the US

\begin{tabular}{|l|l|}
\hline Europe & United States \\
\hline Specialist (single topic SNP) & Generalist (Facebook groups) \\
\hline Top-down (Government initiative) & Bottom-up (Party campaign activism) \\
\hline Dealing with policy issues & Having electoral purposes \\
\hline $\begin{array}{l}\text { The presence of lively debates increases reputation and } \\
\text { attractiveness, thus Google driven traffic }\end{array}$ & $=$ \\
\hline Both can induce mass imitation and multiplicative effects (but at different action levels presumably) \\
\hline
\end{tabular}

A recommendation for European policy makers could then well be the following: build an ICT infrastructure (better if Open Source) for social networking whenever the topics under discussion are limited in scope, but wide in potential implications. This can justify moving forward from "oneoff" and "ad-hoc" participation experiments, particularly towards permanent coverage of Public Administration's mission critical functions.

Some ideas that we would like to highlight in support of this view are the following:

1. "Collective wisdom" (Surowiecki 2004) ensures the emergence of more and better ideas that nobody on their own could ever provide. In this respect, as confirmed by other Preparatory Action projects on eParticipation realised in Europe (Charalabidis et al. 2009), public decisionmaking has always much more to gain than to lose in terms of quality, efficiency, timeliness, and efficacy, from a structured recourse to citizens' involvement and political participation;

2. The alternation of "online" (=discussion) and "offline" (=awareness raising) moments remains critical to warm up any participatory process, including a social networking site. Citizens are not easily engaged at all; it is up to Governments to make (even more than just) the first move towards them (Ferro and Molinari 2009);

3. Prior distribution of thematic information is essential to ensure constructive and fruitful discussions on the proposed topics. Actually it is what distinguishes participation from instant polling;

4. Reputation is built up with time. One should not be eager for immediate results. This is also why sufficient time must be allowed in order for (electronic) participation practices to mature and take-off properly in any given context, particularly where there is physical and time distance between the advice given and the policy-making level in charge of related decisions ${ }^{12}$;

5. The link between participation in social networks and individual/collective engagement in public life deserves better exploration, particularly in all those contexts where small changes in daily behaviour can induce mass imitation and multiplicative effects. Climate change, energy and sustainable development are undoubtedly among these contexts, which have already paved the way for some international initiatives (European Commission 2010, ePractice 2010, World Health Organisation 2008) while possibly needing a more dedicated focus to local community building from national and regional policy makers in Europe.

\footnotetext{
${ }^{12}$ In the IDEAL-EU case, "impact [on EU level decision-making] was actually produced, in highlighting the strategic value of local level actions and citizens involvement'. Interview to MEP Guido Sacconi. Brussels, $3^{\text {rd }}$ March 2009. Unofficial English translation available at the corresponding author.
} 


\section{References}

Anderson, C. (2004). "The Long Tail". Wired Magazine 12 (October). Retrieved February 28, 2010 from: http://www.wired.com/wired/archive/12.10/tail.html

Charalabidis, Y., Kipenis, L., \& Koussouris, S. (2009). E-Participation Projects Consolidated Results. Deliverable 2.7 of the MOMENTUM Coordination Action. European Commission, e-Participation Workprogramme. Retrieved February 28, 2010 from: http://www.ep-momentum.eu/KnowledgeBase/tabid/81/Default.aspx

European Commission (2010). DG Environment portal: "Change. How can you control climate change?". Retrieved February 28, 2010 from: http://ec.europa.eu/environment/climat/campaign/index en.htm

Ferro, E., \& Molinari, F. (2009). "Making Sense of Gov 2.0 Strategies: 'No Citizens, No Party'”. In A. Prosser \& P. Parycek (Eds.), Proceedings of the eDEM2009 Conference (pp. 171-182), Vienna: OCG. ISBN: 978-3-85403-251-9.

Hill R.A. \& Dunbar R.I.M. (2003). "Social Network Size in Humans". Human Nature 14 (1), pp. 53-72.

IDEAL-EU Project (2008). Deliverable D3.1 "Pilots Description”. Retrieved February 28, 2010 from: http://www.ideal-eu.net

Kelly, C. (2007). Five Main Ways to Use Social Networking in Politics. New Politics Institute. Retrieved February 28, 2010 from: http://www.newpolitics.net/sites/ndn-newpol.civicactions.net/files/NPI Leverage Social Networks.pdf

Marcelo K.B., Lopez M.H., Kennedy C., \& Barr K. (2008). Young Voter Registration and Turnout Trends. CIRCLE/Rock the Vote. Retrieved February 28, 2010 from: http://www.civicyouth.org

Morgan Stanley Research (2009). "Economy + Internet Trends. March 20, 2009". Retrieved February 28, 2010 from: http://www.slideshare.net/tcrock08/techtrends032009final

Nielsenwire (2010). "Led by Facebook, Twitter, Global Time Spent on Social Media Sites up 82\% Year over Year". Retrieved February 28, 2010 from: http://blog.nielsen.com/nielsenwire/global/led-by-facebook-twitter-global-timespent-on-social-media-sites-up-82-year-over-year/

Rogers, E. M. (1962). Diffusion of Innovations. Glencoe: Free Press.

Surowiecki, J. (2004). The Wisdom of Crowds. New York: Anchor Books.

ePractice (2010). The Environmental Democracy via ICT Blog. Retrieved February 28, 2010 from: http://www.epractice.eu/community/envirodemocracy/blog/

Wellmann, B. (2001). "Computer Networks As Social Networks". Science Magazine, 293 (September). Retrieved February 28, 2010 from: http://www.sciencemag.org

Wikinews (2010). "People limited to 150 friends, despite Facebook, says academic". Retrieved February 28, 2010 from: http://en.wikinews.org/wiki/People limited to 150 friends, despite Facebook, says academic?dpl id=149591

World Health Organisation (2008). "Protecting Health from Climate Change. World Health Day 2008. Annex 1: Reducing your carbon footprint can be good for your health. A list of mitigating actions". Retrieved February 28, 2010 from: http:// www.who.int/world-health-day/toolkit/dyk whd2008 annex1.pdf

\section{About the Authors}

Francesco Molinari

Francesco Molinari holds an MSc and a MA in Local Public Management (Siena University, 2007 \& 2005) and a BSc in Social and Economic Disciplines (Milan "L. Bocconi” University, 1990). He is also a late PhD Scholar on Public Management at the Department of Business and Social Studies of Siena University. Currently an independent researcher and project manager for several public and private organizations in Europe, from 2009 on he has been associate to the London based 21C Consultancy firm, and Director of the innovative start-up company SmartIntuitions, based in Nicosia, Cyprus. Between 2007 and 2008 he joined the International Research Unit at ALTEC SA, the second largest ICT Company of Greece for $R \& D$ expenditure, holding the responsibility for eGovernment research. Between 2003 and 2006 he was a contract professor at Pisa University, designer of the eGovernment module at the Political Science Faculty. His background includes 5 -years service as strategic advisor of a middle-sized Italian City Mayor.

\section{Erika Porquier}

Erika Porquier holds a Laurea degree in Economics at the University of Pisa (2000) and a MA in project management (2010). She also has a specialization in European project management (2007). Since 2003 she has been involved as coordinator/participant in several European and National projects in the field of information and communication technology. These have mostly involved the public sector (at any level) in its relationship with citizens/users (e-government, edemocracy, e-participation). She is an expert on social networks and web 2.0 tools. 